\title{
¿Es tolerable la tolerancia religiosa?
}

\author{
Is religious tolerance tolerable?
}

\author{
FERNANDO SAVATER \\ Universidad Complutense, Madrid
}

\begin{abstract}
RESUMEN. La tolerancia es un valor básico de nuestras democracias, en cuanto se refiere a actitudes vitales y a interpretaciones simbólicas de nuestra experiencia. No suele haber tolerancia, en cambio, sobre las cuestiones de hecho presentadas sin base científica o desde presupuestos comprobadamente falsos. Las religiones tienen una dimensión poética y simbólica no sólo tolerable sino hasta enriquecedora de nuestra interpretación vital, pero casi siempre pretenden presentarse también como explicaciones de los hechos en competencia con la de los científicos. Puede cuestionarse si debe haber plena tolerancia para este segundo uso de la ideología religiosa.
\end{abstract}

Palabras clave: Tolerancia, interpretación simbólica, ideología religiosa.
ABSTRACT. Tolerance is a basic value of our democracies, when it applies to life attitudes and to symbolic interpretations of our experience. However, usually there is no tolerance about statements of fact offered without scientific basis or from assumptions that proved to be false. Religions have a symbolic and poetic dimension which is not only tolerable, but even also fruitful for the interpretation of our life, but they also tend to present themselves as explanations of facts in competition with scientific explanations. It can be argued whether complete tolerance of this second use of religious ideology should be encouraged.

Key words: Tolerance, symbolic interpretation, religious ideology.

Vivimos una época — supongo que hay que añadir «afortunada»— en la cual toda forma de tolerancia se recomienda prácticamente sola, mientras que intolerancias, prohibiciones y cualquier otro tipo de intransigencia nunca logran justificarse plenamente y siempre dejan un regusto de arbitrariedad dictatorial. La tolerancia universalmente recomendada no se refiere, empero, a conocimientos propiamente dichos sino a formas de vida o a interpretaciones de sentido digamos «existencial». En el terreno que cubre la ciencia, con su visión objetiva, experimental, contrastable y a menudo formalizable de la realidad, el margen de tolerancia hacia saberes basados en leyendas y tradiciones inverificables es sumamente reducido. Aceptamos con bastante naturalidad que un creyente en la reencarnación de las almas se haga oír en un congreso de teología o en un curso de antropología, pero no admitimos que haya cáte- 
dras de astrología en las universidades serias o que se incluya el espiritismo como asignatura en la escuela pública. Por decirlo recurriendo a una metáfora que se remonta a muchos siglos atrás, el mundo en que vivimos y del que formamos parte es un libro cuyo mensaje poético puede interpretarse de muy diferentes modos, pero que está escrito en una lengua cuya sintaxis y semántica elemental las establece de forma universal el método científico.

La generalización de la tolerancia es sin duda una consecuencia del reconocimiento de derechos fundamentales idénticos para todos los humanos, o sea de un concepto de igualdad que significa - como bien ha hecho notar Odo Marquard- «que todos podamos ser diferentes sin temor». Tenemos derecho a ser diferentes: es decir, compartimos el derecho, no la diferencia. Naturalmente, el derecho a la diferencia es igual para todos, o sea que no equivale a una diferencia de derechos. Volveremos sobre las consecuencias de este principio, esencial para la correcta comprensión del concepto actual de tolerancia. Baste ahora señalar que para alcanzar el objetivo - la libre diferencia sin temor - es imprescindible establecer el derecho común a una humanidad que en tanto compartida no es desde luego «diferente» sino plena y consecuentemente semejante. Aquello en que no diferimos (y que nos hace humanamente semejantes, más allá y sobre todo antes de cualquier diferencia) es el fundamento de unas diferencias ni temibles ni temerosas, que expresan nuestra libertad y por tanto la búsqueda abierta de nuestro destino.

¿Qué es lo que compartimos? O, por decirlo de otro modo: ¿a qué llamamos humanidad? Cada uno de nosotros (creo que esto puede establecerse por igual dentro de cualquier cultura y en cualquier época, aunque con diversas fórmulas expresivas) advierte que vivir es juntamente una función biológica y una experiencia simbólica. Ambos aspectos permanecen en constante interrelación, cuyas incidencias y altibajos acertamos a comprender de manera muy parcial. Por ello es una permanente tentación tratar de entenderlos por separado, como formas de vida puras o - por utilizar la expresión clásica- absolutas. Una función biológica que nada debe a la experiencia simbólica, una experiencia simbólica que puede desligarse triunfalmente de su función biológica. Incluso hemos acuñado figuras para que protagonicen estos absolutos: el Animal, que es biología libre de símbolos, y el Angel o el Dios, que es simbología no biológica. Ambas figuraciones presentan dificultades, porque sabemos que los animales existen pero ignoramos el nivel simbólico de su intimidad experimental y conocemos íntimamente lo que simbolizan ángeles y dioses pero podemos dudar seriamente de que existan. No lograremos identificarnos plenamente con unos o con otros sin mutilarnos y desde luego sin malentendernos radicalmente.

Tampoco los intentos de jerarquizar ambas vertientes de la misma realidad vital humana, priorizando la función biológica (como hacen por ejemplo la neurociencia y la psicología evolutiva) o la experiencia simbólica (como propugna el idealismo metafísico y poético) obtienen resultados más inase- 
quibles al desaliento de la contradicción y la crítica. A la sabia admonición pascaliana de que quien pretende a toda costa hacerse el ángel termina haciendo el animal podemos añadirle un reverso de precaución contra el cientifismo, especialmente útil en la actualidad: los que se empeñan en animalizar nuestra condición simbólica terminan por reducir a estrategia evolutiva las alas del querubín. Y que nadie pida ayuda a nuestra herencia ilustrada, porque la ilustración consiste en desvelar y revelar tanto las formas antiguas como las nuevas de superstición.

De modo que nuestra condición bifronte (ipero única!) presenta distintas exigencias intelectuales: la supervivencia biológica exige un conocimiento razonado y verificable, empíricamente sustentado, de la realidad objetiva (impersonal y no elegida, la que ofrece resistencia a la urgencia de los deseos) en que transcurre nuestra existencia, mientras que la experiencia simbólica - referida a la otra dimensión de nuestra existencia, interpersonal y ávida de significados en que reconocernos- necesita disponibilidad y apertura de la imaginación creadora. La tolerancia es requerida para facilitar tales empeños, distintos y complementarios. Y por tanto también tiene características diferentes, según el terreno intelectual en que se aplica: debe haber tolerancia para la investigación científica, sin cortapisas ideológicas supersticiosas que obstaculicen o prohíban la comprensión cada vez más fiable del mapa completo y el manual de instrucciones para el manejo de la realidad; y no menos tolerancia para el libre juego de la imaginación que busca significados humanos o sobrehumanos a nuestra experiencia de vivir junto a semejantes entre lo que sabemos y lo que ignoramos, descubriendo o inventando objetivos para una existencia de cuya fragilidad irrepetible somos inmediatamente conscientes. Hasta aquí, más o menos, la cuestión está aceptablemente clara. La verdadera dificultad comienza cuando estas tareas intelectuales se salen de sus goznes - como los tiempos en que vivimos, según la célebre queja de Hamlety pretenden dictar su arbitrio fuera del campo de juego en el que tienen razonable competencia.

Por supuesto, no me refiero a las lógicas y esperables contaminaciones entre labores de la ciencia y artes de la imaginación: la condición humana es única, como ya hemos dicho, y la agobiante urgencia de nuestra vida no tolera a la pedantería ni al escrúpulo establecer infranqueables compartimentos estancos en nuestro múltiple afán de entender para vivir. Los experimentos científicos cabalgan a menudo sobre corceles criados por el anhelo de significado y la experiencia poética de la vida interpreta a partir de cuanto sabemos comprobar y calcular. Todo esto resulta muy comprensible, incluso yo creo que necesario. El problema auténtico comienza cuando la ciencia y la poesía no se limitan a ser cómplices o al menos rivales complementarias sino que tratan de sustituirse mutuamente, suprimiendo a su contraria. Es decir, cuando la poesía pretende saber más que la ciencia respecto al funcionamiento y naturaleza de lo que hay o cuando la ciencia decreta que la vida humana es un 
fenómeno sin trascendencia ninguna - intrascendente como cualquier otrocuyo verdadero significado se agota en su descripción objetiva, que incluye la génesis evolutiva de que procede. Se trata de abusos semejantes, que a veces se responden uno a otro airadamente. La poesía que se toma científicamente en serio a sí misma y pretende tener una explicación del cosmos mejor que la ofrecida por el método científico es lo que suele llamarse «religión»: su única excusa es que se trata de una supervivencia del pasado en que la ciencia era menos que un esbozo y por entonces cumplió la función de calmar la incertidumbre de la ignorancia... tapando la ignorancia con leyendas. En la acera de enfrente está la actitud de quienes confunden el experimento con la experiencia, decidiendo que toda pretensión de significado simbólico — es decir, poético- que no se atenga al materialismo que da cuenta exterior de los efectos y las causas es un engaño nocivo, voluntario o involuntario. Esta pretensión reductora no es, claro, científica sino cientifista - es decir que convierte a la ciencia en ideología - y su única excusa es que responde a la secular agresión contra el conocimiento verificable de las instituciones religiosas, poderosas e inquisitoriales antaño pero también hoy en demasiadas ocasiones y lugares.

A mi juicio, uno de los pensadores que mejor se ha ocupado de este conflicto de jurisdicciones intelectuales es George Santayana en sus «Interpretaciones de poesía y religión». Dado que es un autor menos recordado de lo debido, me permito citarle con cierta extensión: «La excelencia de la religión se debe a una idealización de la experiencia que, aunque ennoblece a la religión cuando se la trata como poesía, la convierte necesariamente en falsa cuando se la trata como ciencia. Su función consiste más bien en extraer de los materiales de la realidad una imagen de ese ideal al que la realidad debería conformarse y, por anticipación, hacernos ciudadanos del mundo que anhelamos»». Por tanto, «las doctrinas religiosas harían bien en abandonar sus pretensiones de ocuparse de cuestiones de hecho. Tal pretensión no sólo es la fuente de los conflictos de la religión con la ciencia y de las vanas y amargas controversias entre sectas, sino que también es causa de la impureza e incoherencia de la religión en el alma, cuando busca sus sanciones en la esfera de la realidad y olvida que su función propia es expresar el ideal» ${ }^{1}$.

Sin embargo, es poco probable que los creyentes en cualquier fe religiosa se conformen con esta sensata caracterización de Santayana. Para ellos, la religión expresa desde luego un ideal, pero un ideal obligatorio, que ha de tener efectos comprobables en la conducta de los humanos y en la organización moral de la sociedad: un ideal ejecutivo, no sólo basado en la realidad bien comprendida sino que también ha de ser realizado en el mundo, en activa polémica con los valores e interpretaciones poéticas que se le oponen. Para los p. 39.

${ }^{1}$ Santayana, George: Interpretaciones de poesía y religión, ed. Cátedra, Madrid, 1993, 
fieles, la creencia religiosa no es fruto de la imaginación humana sino de la revelación divina; y para ellos, podríamos decir parafraseando el famoso dictum de Marx, la cuestión no es sencillamente interpretar nuestra experiencia vital sino transformarla de acuerdo con los dictados de preceptos que nos han sido dados por una autoridad superior.

Las religiones no se ofrecen al creyente como lenguajes metafóricos disponibles para ayudarnos a soportar y si es posible degustar las peripecias de nuestra aventura como seres mortales e irrepetibles - al modo en que podemos disponer de las obras de Shakespeare o Rilke - sino que proponen e incluso imponen un camino doctrinal capaz de salvarnos de nuestra condición vulnerable. Aspiran a brindar una solución sobrenatural a la perplejidad de nuestra condición natural: desde lo sobrenatural resuelven los enigmas de la naturaleza (que así se hace en el fondo mucho más enigmática que nunca) y también establecen las normas de conducta que rescatarán a los humanos de los sufrimientos y la muerte. Y precisamente esa inverosímil osadía —ofrecer no sólo respuestas contundentes e inverificables sino remedios para cuanto padecemos y tememos - es la base del éxito popular de las religiones en nuestra era tan atribulada como cualquier otra pero más escéptica que la mayoría de las anteriores.

Y de nuevo volvemos a tener que plantearnos la cuestión de la tolerancia. Por supuesto, nada hay que objetar democráticamente a ninguna creencia religiosa mientras se mantenga en el antes expresado registro simbólico y poético: responde a la libertad de conciencia y por tanto es un derecho de cada cual. El problema es que los auténticos creyentes no sólo ven su religión como un derecho personal, sino como una obligación: para ellos mismos pero también para los demás y para la sociedad en su conjunto. Y creen tener argumentos trascendentes para rechazar las leyes que van contra sus convicciones y para exigir que se dicten otras de acuerdo con la normativa divina. Cuando se trata de creencias individuales el problema es menor, pero se agrava cuando intervienen las organizaciones jerárquicas de fieles religiosos, es decir las iglesias. Cada iglesia o corporación religiosa es una estructura de poder con pretensiones de control e influencia social que intenta hacer prevalecer la respuesta sobrenatural sobre cualquier otra de índole científica, política, jurídica, etc. ... En su esencia misma está la intransigencia, porque lo que no se basa en razones difícilmente acatará ceder ante la crítica racional: lo único que ha convertido en tolerantes - con muchas renuencias - a las grandes iglesias monoteístas es la debilidad política y la pérdida de peso social. Admitamos que, mientras se atengan en sus procedimientos al juego democrático, tienen tanto derecho - aunque nunca más, desde luego- para hacerse oír en el debate público como cualquier otro grupo ideológico. Por supuesto, lo que sería inadmisible es permitir que por motivos doctrinales difundan soflamas llamando a la subversión de las instituciones civiles y no digamos ya si convocan a cometer crímenes «sagrados» o discriminaciones de cual- 
quier tipo entre ciudadanos (en razón de su sexo, por ejemplo). En cuestiones de hecho o de derecho (científicas, legales, etc. ...) no cabe exigir dispensa alguna por razones religiosas, puesto que la religión es siempre una opinión privada que no puede imponerse a todos en nombre de ninguna autoridad extra o sobrehumana. Puede reclamar respeto, pero no más que el que merecen quienes la desmienten: y desde luego, nunca será respetable la atrocidad, el crimen o la jerarquización de los humanos, por «santas» que sean las razones que las abonen.

En los estados de derecho consecuentemente laicos (es decir, democráticos, porque el laicismo es inseparable de la democracia si se toma a ésta mínimamente en serio) el papel de las creencias religiosas y sobre todo de las iglesias está convenientemente restringido: puede ejercerse libremente pero siempre dentro del marco de las leyes civiles. La argumentación de los creyentes en cuestiones de valoración y de moralidad ha de ser atendida aunque - como ha señalado Habermas - siempre que se exponga buscando razones que puedan también ser comprendidas por quienes no compartan su misma fe, no como dogmas revelados y por tanto indiscutible, inapelables. En este aspecto, es inaceptable que los partidarios de lo sobrenatural apelen a una supuesta «Ley Natural» ante la que deberían arrodillarse todas las dudas y cuestionamientos de quienes sólo creen en una razón meramente humana, iluminada por la discusión con los semejantes pero no sometida a ninguna revelación divina. Y, por supuesto, los primeros que deberían dar ejemplo de neutralidad religiosa tendrían que ser los gobernantes, renunciando a cualquier justificación sobrenatural de sus decisiones políticas o a exhibir en ceremonias civiles aparato religioso de cualquier clase. También renunciando a privilegiar el punto de vista religioso fideísta - aunque sea plural - frente a la incredulidad, tan «religiosamente» digna de reconocimiento como cualquier creencia. En este terreno, Mahoma, Santo Tomás de Aquino, el Dalai Lama o el Papa no gozan de ninguna prioridad intelectual ni moral sobre Voltaire, Freud o Nietzsche.

Pero el punto más escabroso es el de la educación. Como se ha señalado, en cuestiones de hecho - científicas, para entendernos- las explicaciones religiosas son inapelablemente inaceptables: es decir, son falsas porque ningún hecho verificable podría falsarlas (según lo exigido por Popper) o comprobarlas jamás. Ni siquiera es concebible qué tipo de evidencia probatoria podría servir para demostrarlas ${ }^{2}$. Y si son inaceptables como tales explica-

2 Algunos objetan que también la democracia se basa en principios igualmente indemostrables. Pero los principios políticos no pretenden ser verdades de hecho (aunque a veces se formulen como si lo fueran: «todos los hombres nacen libres e iguales») sino de derecho, es decir, convenidos por los humanos de manera más o menos explícita. La verdad de los principios es el acuerdo que los sustenta y las razones humanamente inteligibles que los apoyan. Por tanto son «verificables» o «demostrables» de la manera que les es propia: ya Aristóteles, en su Ética a Nicómaco distingue entre lo que se puede probar con exactitud (en las ciencias naturales) y lo que sólo puede probarse con rigor (en las ciencias humanas). 
ciones, también lo serán como vía de aprendizaje para los neófitos, que además tienen menos recursos intelectuales para prevenirse de ellas. ¿Es por tanto tolerable la tolerancia de una enseñanza religiosa? No me refiero obviamente a la educación pública, de donde debe ser excluida por elemental lógica democrática, sino incluso en los colegios privados. ¿Podemos las personas laicas, preocupadas por la educación (que ha de ser siempre un esfuerzo hacia la veracidad o al menos hacia la probabilidad racionalmente mejor fundada, aunque deba de permanecer abierta y revisable) aprobar en nombre de la libertad que se enseñen falsedades o explicaciones inverificables a quienes menos pueden defenderse ante ellas?

Y no sólo en cuestiones científicas objetivas, sino también en el terreno de la moral y los valores que debemos compartir: ¿ es asumible que se imparta una formación en estas materias que deje entender que no hay más obligaciones y preceptos éticos que los emanados por una autoridad sobrenatural o los que concuerdan sumisamente con ellos? Si la libertad de enseñanza prima por encima de cualquier otra consideración, ¿por qué la nigromancia o el espiritismo, así como la doctrina de la existencia de razas superiores, están formal y universalmente excluidas de los planes de estudio?

Para el creyente, su fe no es solamente una vía poética de interpretación del mundo - como quería Santayana - sino, ante todo, una fórmula para responder a las preguntas cosmológicas de manera taxativa y sobre todo una guía de cómo comportarse en el mundo. Si se adoctrina en una fe religiosa se adoctrina en una forma de comportamiento que no puede ser puesta en duda porque proviene directamente de la misma divinidad, eso sí, vía clérigos: en ocasiones serán preceptos conservadores, en otros casos milenaristas y revolucionarios, en cualquier caso siempre dictados desde lo alto y no acordados entre los humanos. Tolerar cualquier enseñanza en materia de religión no es tolerar cualquier forma de pensar sino cualquier forma de educar para vivir en sociedad. En nuestras sociedades abiertas y democráticas, pocos se atreven a negar esta tolerancia aunque no es difícil darse cuenta de sus peligros. Sam Harris es uno de los pocos que han expresado abiertamente una opinión discrepante: «Dado el vínculo que existe entre creencia y acción, está claro que no podemos ser más tolerantes con la diversidad de creencias religiosas que con una diversidad de creencias acerca de epidemiología o higiene básica» ${ }^{3}$.

Personalmente, creo que es una objeción digna de tenerse en cuenta. Pero corremos el peligro de que sólo sean perseguidas las supersticiones foráneas mientras que se acepten sin escándalo mayor las tradicionales en nuestras comunidades: para entendernos, que se censure como irracional la ablación del clítoris y se asuma como edificante el discurso del Papa contra el control de natalidad, por ejemplo. A veces parece «razonable» lo que no es sino una superstición habitual en nuestros pagos. Quienes preferimos que haya las me-

${ }^{3}$ Harris, Sam: The End of Faith, Free Press, Great Britain, 2006, p. 46. 
nos prohibiciones posibles en esta sensible materia, debemos al menos reivindicar una libertad de crítica a la religión no menor de la que se concede a la religión misma. Es decir, que en todos los campos - y especialmente en la escuela - permanezca abierta la opción de denunciar la falsedad o la nocividad de las creencias religiosas en cuanto abandonan su papel poético y simbólico para pretender competir con la ciencia o con el discurso político. Ya sé que esto es difícil de llevar a cabo de manera institucional sin parecer intransigente, pero conviene recordar que en ciertas cuestiones una dosis de intransigencia forma parte insustituible de la salud mental y moral. 